\title{
Development of Partial Tolerance to the Gastrointestinal Effects of High Doses of Recombinant Tumor Necrosis Factor- $\alpha$ in Rodents
}

John S. Patton, Pamela M. Peters, James McCabe, Dietrich Crase, Stan Hansen, Anthony B. Chen, and Denny Liggitt

Department of Pharmacological Sciences, Genentech, Inc., South San Francisco, California 94080

\begin{abstract}
Treatment of healthy rats and mice with a single intravenous injection of recombinant human tumor necrosis factor-alpha (rHuTNF- $\alpha$ ) caused a dose-dependent gastrointestinal inflammation. Within 30 min gastric emptying was blocked and tissue edema occurred in the small and large intestine. In the cecum hemorrhage occurred after $4 \mathrm{~h}$ at doses $\geq 250 \mu \mathrm{g} / \mathrm{kg}$. The cecum exhibited an acute inflammatory response following rHuTNF- $\alpha$ treatment similar to that seen in tumor necrosis at the same dose. The vascular endothelium became swollen, increased numbers of neutrophils and other leukocytes attached to and penetrated the endothelium, and finally hemorrhage occurred. Treatment of rats with daily injections of rHuTNF- $\alpha$ (250 $\mu \mathrm{g} / \mathrm{kg}$ per d) for $3 \mathrm{wk}$ failed to produce cachexia. Within 24-48 $\mathrm{h}$ rats became resistant to the hemorrhagic effect of rHuTNF- $\alpha$, however, the cytokine still caused a transitory block of gastric emptying after $10 \mathrm{~d}$ of treatment. Treatment at 5- or 10-d intervals produced results similar to the initial injection. These results suggest that maximum hemorrhagic response will occur when rHuTNF- $\alpha$ is administered at intervals of 5-10 d rather than daily.
\end{abstract}

\section{Introduction}

In 1975 Carswell et al. discovered a factor in the serum of bacteria primed, endotoxin-treated animals that could induce hemorrhagic necrosis of tumors in recipient animals (1). They called this active principle tumor necrosis factor (TNF). ${ }^{1}$ Since then, two TNFs have been isolated and characterized; TNF- $\alpha$, a product primarily of macrophages and to a lesser degree natural killer cells, natural cytotoxic cells, and interleukin 3 dependent bone marrow-derived mast cells, and TNF- $\beta$, a product of B-lymphoblastoid cells (2). The TNFs are now known to be members of a larger group of inducible hormonelike proteins called cytokines that help regulate the host metabolic and immunological response to infection.

The mechanism of tumor necrosis by TNF is poorly understood although evidence suggests that TNF induces a classical acute inflammatory response in the tumor that leads to

Address reprint requests to Dr. Patton.

Received for publication 29 December 1986 and in revised form 8 June 1987.

1. Abbreviations used in this paper: GI, gastrointestinal; Meth A, methylcholanthrene $\mathrm{A}$; rHuTNF- $\alpha, \beta$; recombinant human tumor necrosis factor-alpha, beta; TNF, tumor necrosis factor.

J. Clin. Invest.

(c) The American Society for Clinical Investigation, Inc.

$0021-9738 / 87 / 12 / 1587 / 10 \quad \$ 2.00$

Volume 80, December 1987, 1587-1596 disruption of the tumor's blood supply $(3,4)$. Palladino et al. have shown that subcutaneously implanted methylcholanthrene (Meth A) tumors, which are well vascularized, are necrosed by TNF- $\alpha$, while intraperitoneal tumors of the same cells, which are poorly vascularized, are not affected by TNF- $\alpha$ (4). They further showed that, in vitro, the Meth A tumor cells were relatively insensitive to TNF (4). Thus, the primary tumor lesion induced by TNF- $\alpha$ in the Meth A model appears to be vascular. Others have shown that TNF- $\alpha$ stimulates neutrophil adherence to endothelial cells in vitro by increasing the affinity of both cells for each other $(5,6)$ and that TNF- $\alpha$ activates the cytotoxic and phagocytic activities of neutrophils (7), which, if directed towards endothelial cells, could destroy them (8). Both of these events are components of the inflammatory response (9) and may contribute to the passage of phagocytic cells and other cells through endothelium. It is still unclear, however, how much of TNF's antitumor effects are due simply to effects on the vasculature of the tumor. In vitro TNF has direct cytotoxic activity against a variety of tumor cell lines (10) and can stimulate the tumoricidal activity of macrophages (11). Thus TNF-induced tumor regression in the absence of hemorrhagic necrosis should be possible, particularly with TNF-sensitive intraperitoneal tumors (12).

Suppression of food intake and anorexia commonly occur during infection. In experiments where anorexia in mice acutely infected with Listeria monocytogenes was overriden by force feeding, mortality was increased and survival time shortened in force fed animals (13). Murray and Murray have summarized the literature on the inhibition of infection by famine and its activation by refeeding; they suggest that loss of appetite in infected animals plays a vital role in host defense as part of a purposeful redistribution of nutrients that contributes to "nutritional immunity" during infection $(14,15)$. There is now evidence that suppression of food intake may be caused by endogenous cytokines. In human clinical trials with alpha and gamma interferon, anorexia, nausea, and vomiting were frequent side effects $(16,17)$. In studies with fasted rats, both Escherichia coli endotoxin and interleukin 1 (another cytokine) have been shown to suppress food intake (18). In addition, Cerami and co-workers have shown that a solution of macrophage secretory products, which may contain interleukin 1 (19) as well as TNF- $\alpha$, induced suppression of food intake in mice (20). Thus interferons, interleukins, and TNFs have all been implicated as causative agents in suppression of food intake during infection.

In this study we have examined the effects of rHuTNF- $\alpha$ on gastrointestinal (GI) structure and function in rodents. The results suggest that rHuTNF- $\alpha$ suppresses food intake by inhibiting gastric emptying as a prelude to an inflammatory response in intestinal tissue. At high rHuTNF concentrations, hemorrhage occurs in rat cecum in a manner similar to that seen in TNF-treated tumors. 


\section{Methods}

Cytokines. Recombinant human tumor necrosis factor-alpha (rHuTNF- $\alpha$ ), -beta (rHuTNF- $\beta$ ), recombinant murine tumor necrosis factor-alpha (rMuTNF- $\alpha$ ), and recombinant murine interferon gamma (rMuIFN- $\gamma$ ) were produced in Escherichia coli as described (21-24). Purified cytokines were administered to animals in phosphate buffered saline (PBS). rHuTNF- $\alpha$ contained $<0.025 \mathrm{pg}$ endotoxin $/ \mathrm{mg}$ protein and $\mathrm{rHuTNF}-\beta<0.05 \mathrm{pg}$ endotoxin/mg protein as determined by the Limulus amebocyte lysate assay.

Animals. Male and/or female Sprague-Dawley rats ( 190-210 g) and female mice (C57BL/6) $(\sim 18-20 \mathrm{~g})$ were obtained from Charles River Laboratories (Portage, MI) and fed ad lib. with autoclavable rodent chow (5010; Ralston-Purina Co., St. Louis, MO). Animals were maintained on a 12 -h light-dark cycle.

Acute single injection experiments. Experiments were begun in the morning between 8 and 9 a.m. near the beginning of the light cycle when the animals normally are inactive and/or sleeping (after a night of feeding and activity). Animals were injected intravenously in the lateral tail vein with 0.1 to $0.3 \mathrm{ml}$ PBS containing cytokine. After injection they were returned to their cages for 1.5-24 $\mathrm{h}$ and then euthanized by carbon dioxide gas (rats) or by cervical dislocation (mice). If a single blood sample was to be drawn from rats at the end of an experiment they were first anesthetized with ketamine $(30 \mu \mathrm{g} / \mathrm{kg})$ and acetylpromazine $(0.75 \mu \mathrm{g} / \mathrm{kg})$. Blood was then drawn from the ventral aorta or the heart and allowed to clot for $30 \mathrm{~min}$ at room temperature, centrifuged, and the serum (on ice) sent to MetPath Labs (Teterboro, NJ) for Chem-Screen Profile and complete blood count with differential.

When animals were returned to their communal cages (five to six rodents per cage) after receiving injections, they were again given free access to food and water. Injection of rHuTNF- $\alpha$ caused an apparent distension of the stomach, which reached its maximum size at $\sim 3.5 \mathrm{~h}$ after injection. Because of this a number of analyses were made at 3.5 h. To determine the effect of the injection on defecation, animals were placed in cages fitted with screens that permitted collection of fecal material. Animals were killed at intervals and their gastrointestinal tracts removed. Stomach and cecal contents were extruded and weighed wet.

To determine the effect of rHuTNF- $\alpha$ on gastric emptying and small intestinal transit time, mice were injected with $5 \mu \mathrm{g}$ rHuTNF- $\alpha$ in $0.1 \mathrm{ml}$ PBS i.v. or PBS alone i.v., and then at appropriate times orally gavaged with $0.2 \mathrm{ml}$ distilled water containing $0.4 \mu \mathrm{Ci}$ of nonabsorbable sodium chromate-51 (250-500 mCi/mg Cr) (Amersham Corp., Arlington Heights, IL). Animals were killed by cervical dislocation at $\sim 30 \mathrm{~min}$ after administration of the ${ }^{51} \mathrm{Cr}$. Stomach, small intestine, and cecum plus colon were removed from each animal and the small intestine cut into eight equal segments. A total of 10 tissue samples per animal were then counted for labeled chromium using a gamma counter.

Chronic multiple injection experiments. The effects of daily injections of rHuTNF- $\alpha$ on body weight, food and water consumption, and urine and fecal output were measured over 10-d and 3-wk periods. In the first experiment nine rats were weighed and then acclimated to Nalgene metabolic cages (Harvard Bioscience, South Natick, MA) for $4 \mathrm{~d}$ during which time their consumption and their excretions were measured. At the beginning of the fifth day, three control animals were injected with $0.1 \mathrm{ml}$ PBS i.v. and six test animals with $0.1 \mathrm{ml}$ PBS plus $50 \mu \mathrm{g} \mathrm{rHuTNF}-\alpha(0.25 \mathrm{mg} / \mathrm{kg}$ i.v. $)$. For the next $20 \mathrm{~d}$ the animals received daily injections of the same doses and their consumption and excretions were measured. On days 5, 10, and 17 injections were intravenous; however, to minimize the loss of feces and urine that occurs when animals are restrained for intravenous tail injections, all other injections were intramuscular. At the end of the experiment, the animals were weighed, anesthetized, blood was drawn and assayed for blood chemistry, and their spleens were weighed. In a second experiment, three rats were given rHuTNF- $\alpha(0.25 \mathrm{mg} / \mathrm{kg}$ i.v. $)$ at 5 - or $10-\mathrm{d}$ intervals. In this last experiment only food intake was measured. In a third experiment, rats were injected daily with PBS, $0.025 \mathrm{mg} / \mathrm{kg}$, or $0.25 \mathrm{mg} / \mathrm{kg}$ rHuTNF- $\alpha$ for $10 \mathrm{~d}$. On days 1 and 5 injections were intravenous, all others were intramuscular. On day $10,3.5 \mathrm{~h}$ after the last intramuscular injection, half of the animals (three to five) from each group were fixed for histology. The remainder were injected one final time on day 11 with PBS or $0.25 \mathrm{mg} / \mathrm{kg}$ rHuTNF- $\alpha$ i.v. and their stomach contents weighed $3.5 \mathrm{~h}$ after injection.

Time course of antibody formation in rats. The purpose of these experiments was to determine the time course of antibody production in response to daily injections of rHuTNF- $\alpha(0.25 \mathrm{mg} / \mathrm{kg})$. The experiment was identical to the metabolic cage study except that consumption and excretions were not measured and only the first injection was intravenous with remaining injections intramuscular. 21 animals were used and groups of three were killed on days $0,3,5,7,9,11$, and 21 after receiving $0,2,4,6,8,10$, and 20 injections of rHuTNF- $\alpha$, respectively. Animals were anesthetized $24 \mathrm{~h}$ after their last injection and their blood was drawn from the ventral aorta and stored at $-70^{\circ} \mathrm{C}$ until analyzed for antibodies to rHuTNF- $\alpha$. Antibody titers to rHuTNF- $\alpha$ were determined by a radioimmune precipitation assay. rHuTNF- $\alpha$ was labeled with ${ }^{125}$ I by the Iodogen method as described by Aggarwal et al. (25) to a specific activity of 30-60 $\mu \mathrm{Ci} / \mu \mathrm{g}$. Dilutions of test sera were incubated with $5.35-10.7 \mathrm{nCi}(20,000 \mathrm{cpm})$ of ${ }^{125} \mathrm{I}-\mathrm{rHuTNF}-\alpha$ for 12-16 h. Immunoglobins were then precipitated by a specific second antibody, goat anti-rat IgG (Antibodies, Inc., Davis, CA), and the radioactivity in the pellets was counted. The titer was defind as the serum dilution that precipitates twice the number of counts precipitated by preimmune serum.

Neutralizing anti-rHuTNF- $\alpha$ antibody activity was estimated by incubating $400 \mathrm{U}(\sim 16 \mathrm{ng}$ ) of rHuTNF- $\alpha$ (in $100 \mu$ l PBS plus $1 \%$ bovine serum albumin) with known volumes of rat serum for 12-16 h at $4^{\circ} \mathrm{C}$ and then assaying for rHuTNF- $\alpha$ activity in the L-M cytotoxicity bioassay for human tumor necrosis factor (26). Neutralizing antibody activity was expressed as nanograms of rHuTNF activity inhibited per milliliter of serum.

Histology. Mice $(20 \mathrm{~g}$, strain C57BL/6) were injected with either 0.25 or $16.5 \mathrm{mg} / \mathrm{kg}$ rHuTNF- $\alpha$ and then killed $3.5 \mathrm{~h}$ postinjection. Their viscera were fixed in 10\% neutral buffered formalin, embedded in paraffin, sectioned, and stained with hematoxylin-eosin. Similarly, rats $(\sim 200 \mathrm{~g})$ were injected with PBS or $0.25 \mathrm{mg} / \mathrm{kg}$ rHuTNF- $\alpha$ i.v. and their gastrointestinal (GI) tracts examined histologically at 1, 4, 6, and $24 \mathrm{~h}$ postinjection. In an additional experiment, rats were injected daily for $10 \mathrm{~d}$ (i.v. on days 0 and 5 and i.m. on all other days) with PBS, $0.025 \mathrm{mg} / \mathrm{kg}$ or $0.25 \mathrm{mg} / \mathrm{kg}$ rHuTNF- $\alpha$ and then examined histologically $3.5 \mathrm{~h}$ after the final intramuscular injection on day 10 .

\section{Results}

Gastrointestinal effects after a single injection. Intravenous injection of rHuTNF- $\alpha$ into healthy mice and rats caused a number of changes in the GI tract. At the time of injection (8-9 a.m.) the animals were entering their rest period after feeding and activity during the night. Immediately after injection, control animals went back to sleep and by $3.5 \mathrm{~h}$ postinjection, most of the food in their stomach had passed into the small intestine and the undigested residue into the large cecum. No defecation by control animals occurred during this period. Fig. 1 shows a schematic drawing of how the control GI tracts appeared $3.5 \mathrm{~h}$ after an injection of PBS (GI contents are shown in black). The GI tracts of rHuTNF- $\alpha$ treated rodents $(0.25 \mathrm{mg} / \mathrm{kg})$ and control animals exhibited striking differences in appearance (Fig. 1). At $3.5 \mathrm{~h}$ postinjection, the stomachs of rHuTNF- $\alpha$ treated rodents were full of food and gas, the small intestine was swollen, and in most cases free of solid contents. The cecum was deflated and defecation had occurred. By 4-6 h the cecum had become hemorrhagic and bloody diarrhea was often noted. Similar results were also seen 
CONTROL

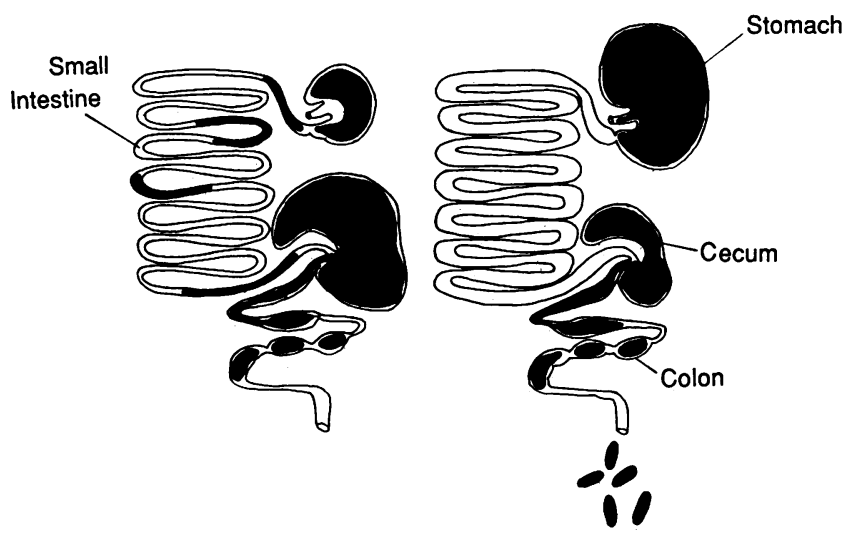

Figure 1. Schematic drawing of rat gastrointestinal tracts as they appear $3.5 \mathrm{~h}$ after a single intravenous injection of $0.1 \mathrm{ml} \mathrm{PBS} \mathrm{(control)}$ or $0.1 \mathrm{ml} \mathrm{PBS}$ plus $0.25 \mathrm{mg} / \mathrm{kg}$ rHuTNF- $\alpha$. Gastrointestinal content and fecal material is shown in solid black.

with rMuTNF- $\alpha$. rMuIFN- $\gamma$ had no apparent effect on the GI tract of mice at doses ranging from 0.005 to $5.0 \mathrm{mg} / \mathrm{kg}$.

The weight of stomach contents was used as an indicator of dose response. A time course study showed that maximal response occurred by $\sim 3.5 \mathrm{~h}$ postinjection and declined to near control values by $7 \mathrm{~h}$ postinjection (data not shown). Fig. 2 shows the effect of increasing doses of rHuTNF- $\alpha$ on the wet weight of stomach contents at $3.5 \mathrm{~h}$ postinjection in mice and rats. Each dosage group contained five to six individuals that were kept in a communal cage. Maximum response in mice was seen at $\sim 0.25 \mathrm{mg} / \mathrm{kg}$; higher doses appeared to decrease the weight of stomach contents. A similar dose response was seen in rats with maximal values occurring between 0.25 and $0.75 \mathrm{mg} / \mathrm{kg}$. Similar results were obtained with rHuTNF- $\beta$ and
rMuTNF- $\alpha$ (data not shown). Fig. 2 also shows the average fecal outputs of rats at different doses of cytokine. These values were calculated from the total weight of feces collected from the group cages. The results show that rHuTNF- $\alpha$ caused an increase in fecal output that roughly paralleled the increase in weight of stomach contents.

To determine whether the increase in weight of stomach contents was caused by inhibition of gastric emptying or an increase in feeding, experiments were conducted to separately test each possibility. In the first, nonabsorbable ${ }^{51} \mathrm{Cr}$ was instilled into the stomachs of mice at $30,60,90$, and $120 \mathrm{~min}$ after they had received a bolus dose of rHuTNF- $\alpha(0.25 \mathrm{mg} / \mathrm{kg}$ i.v.). Mice were euthanized $30 \mathrm{~min}$ after delivery of ${ }^{51} \mathrm{Cr}$ and the location of the radioactivity in different regions of the GI tract determined. Fig. 3 shows results for control and rHuTNF- $\alpha$ treated animals. In control animals, almost all ( $>90 \%$ ) of the total administered ${ }^{51} \mathrm{Cr}$ had moved into the small intestine after $30 \mathrm{~min}$. In cytokine-treated animals, however, the nonabsorbable marker was retained primarily in the stomach. Thus, intravenous rHuTNF- $\alpha$ acts rapidly to block gastric emptying.

To determine if rHuTNF- $\alpha$ also induced feeding, food intake was measured during a $3.5 \mathrm{~h}$ period following a single bolus injection of rHuTNF- $\alpha(0.25 \mathrm{mg} / \mathrm{kg}$ i.v. $)$ or PBS. Control animals ate a negligible quantity of food; $0.05 \pm 0.05 \mathrm{~g} / \mathrm{rat}$ $(n=3)$. Some cytokine-treated animals also ate nothing, but others nibbled occasionally giving an average value for six animals of $0.65 \pm 0.62 \mathrm{~g} / \mathrm{rat}$. Unlike control animals who usually went back to sleep after their injection, cytokinetreated animals stayed awake and exhibited a characteristic hunched posture with their fur erect. Eating, when it did occur, was perfunctory and limited, and ceased entirely by $3.5 \mathrm{~h}$. The increased weight of stomach contents in treated animals as compared to controls can therefore be explained by a marked decrease in gastric emptying and a slight increase in food consumption.

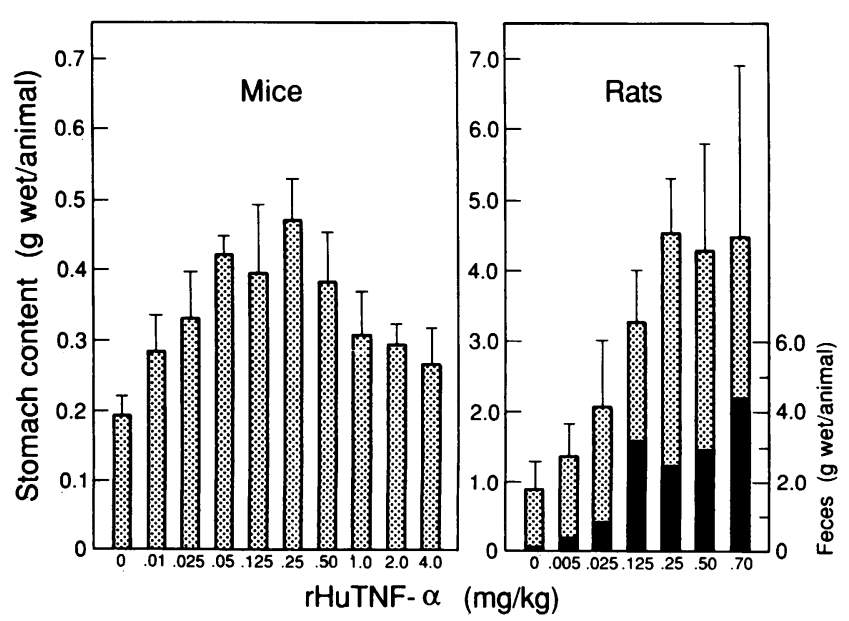

Figure 2. The effect of intravenous dose of rHuTNF- $\alpha$ on the wet weight of stomach contents (stippled bars) in mice and rats and fecal output (solid bars) in rats at $3.5 \mathrm{~h}$ postdosing. Stomach content values are means from five to six individuals $( \pm 1 \mathrm{SD})$. Fecal weights are mean values based on the total pooled fecal weight of five to six rats.

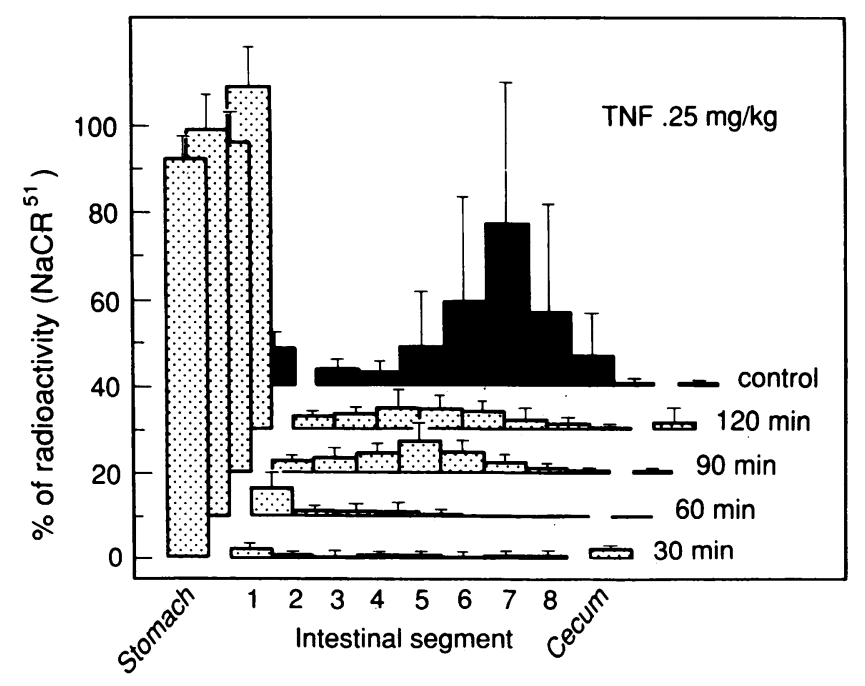

Figure 3. The effect of a single intravenous injection of rHuTNF- $\alpha$ $(0.25 \mathrm{mg} / \mathrm{kg})$ on gastric emptying. $\mathrm{NaCr}^{51}$ was instilled by oral gavage into the stomach of mice at $30,60,90$, and 120 min after they had been injected with rHuTNF- $\alpha$. Disposition of the marker was then assessed after $30 \mathrm{~min}$. Five animals were used per group, error bars $= \pm 1 \mathrm{SD}$. 
Histology after single injection. At $3.5 \mathrm{~h}$ after a single dose of rHuTNF- $\alpha(0.25 \mathrm{mg} / \mathrm{kg})$, both rats and mice exhibited similar histological changes in their small and large intestines compatible with mild enteritis. There was a mild accumulation of mononuclear and fewer neutrophilic inflammatory cells in the lamina propria of villi and intestinal glands. Along with the cell accumulation in the lamina propria there were a few pyknotic and fragmented nuclei and variably severe edema and lymphangiectasia. Another consistent and distinct change affecting those rodents injected with rHuTNF- $\alpha$ involved the vasculature. This change consisted of increased height (prominence) of the endothelium of small vessels, increased adherence of mononuclear and neutrophilic cells to the endothelial surface, and increased numbers of these same cells within vessel lumina.

Mice were also injected with a single very high dose of rHuTNF- $\alpha(16.5 \mathrm{mg} / \mathrm{kg})$ and were examined $3.5 \mathrm{~h}$ postinjection. Stomach dilation was much less prominent than in groups treated with lower doses (Fig. 2). Treated mice had variable degrees of necrosis and inflammation of intestinal mucosa. The necrotic change affected only crypt epithelial cells and was characterized by nuclear pyknosis, karyolysis and, rarely, sloughing of individual cells. There was no ulceration. The small intestine was more severely involved with only minimal involvement of the stomach and large intestine. Inflammatory changes involved the lamina propria of the mucosa and were characterized by accumulation of mononuclear and fewer neutrophilic inflammatory cells and the presence of scattered necrotic cells. These changes resulted in thickening and hypercellularity of intestinal villi lamina propria. Hemorrhagic foci were very rare. Vascular changes were identical to those seen at the lower dose.

Following a single injection of $0.25 \mathrm{mg} / \mathrm{kg}$ i.v. rHuTNF- $\alpha$ no hemorrhage was observed for $\sim 4 \mathrm{~h}$; however, between 4 and $6 \mathrm{~h}$ postinjection, cecal hemorrhage was prominent in all rats treated. Hemorrhage was also noted in a section of uterus that was sectioned from one animal. The small intestine and stomach were rarely hemorrhagic. Fig. 4 shows sections of the cecum from control $(A), 4 \mathrm{~h}(B)$, and $24 \mathrm{~h}(C)$ postinjection rats. At $4 \mathrm{~h}$, edema had caused a marked widening of the submucosa. By $24 \mathrm{~h}$, this edema was extreme. Figs. $4 D-F$ show a sequence of photographs from control $(D), 4 \mathrm{~h}(E)$, and $24 \mathrm{~h}$ $(F)$ postinjection rats that illustrate some of the vascular changes caused by rHuTNF- $\alpha$. Normal vessels (Fig. $4 D$ ) were characterized by flattened endothelial cells (arrows) with few, if any, marginated neutrophils and other leukocytes. After $4 \mathrm{~h}$ (Fig. $4 E$ ) considerable margination of leukocytes (arrows) to hypertrophied endothelium had occurred. By $24 \mathrm{~h}$ the migration and hypertrophy were severe. Various stages of leukocyte margination and endothelial cell hypertrophy are shown in Fig. $4 F$ plus the presence of leukocytes within the vascular wall and marked perivascular edema (asterisks).

Blood chemistry and cell numbers. The profound GI changes caused by rHuTNF- $\alpha(0.25 \mu \mathrm{g} / \mathrm{kg})$ were accompanied by relatively few significant changes in blood components. Of 32 standard blood indices measured, only 3 exhibited significant differences between control and treated animals. Neutrophil numbers were increased, lymphocyte numbers decreased and triglyceride levels were elevated by rHuTNF- $\alpha$ treatment (Table I). At $1.5 \mathrm{~h}$ there was no significant difference in cell numbers between control and treated animals, however, at 3 and $4.5 \mathrm{~h}$ postinjection, neutrophil numbers increased roughly fourfold and lymphocyte numbers decreased two- to fourfold. Triglyceride concentrations were measured only in females and showed a three- to sixfold increase over controls after rHuTNF- $\alpha$ treatment. Blood urea nitrogen (BUN) and creatine concentrations were slightly increased in treated animals (data not shown).

Chronic multiple injection studies. The effects of daily injections of rHuTNF- $\alpha(0.25 \mathrm{mg} / \mathrm{kg})$ on GI function were studied by placing rats in individual metabolic cages and monitoring their daily food and water consumption, and feces and urine production. A total of nine animals were studied in the first experiment (three PBS treated and six-rHuTNF- $\alpha$ treated). Fig. 5 shows the results of a 24-d study. After $3 \mathrm{~d}$, during which the animals became accustomed to their cages, the first intravenous injections were made. This led to a marked drop in the consumption of food and water by the rHuTNF- $\alpha$ treated animals as compared with the control animals in the first $24 \mathrm{~h}$. Bloody stools were seen in four of the six rHuTNF- $\alpha$ animals. After the initial intravenous injection, intramuscular injections of the original dose were given on the next $4 \mathrm{~d}$. During this period, food and water consumption rebounded and the second intravenous injection given on day 5 produced no obvious effect nor did any of the subsequent injections over the next $2 \mathrm{wk}$. The animals rapidly developed tolerance to the inflammatory effects of rHuTNF- $\alpha$ on the GI tract. At the end of the experiment, control animals gained an average of $18 \pm 9 \mathrm{~g}$ and treated animals $29 \pm 10 \mathrm{~g}$. Blood chemistries were identical in both groups and no gross differences between groups were seen except in spleen weights, which averaged $510 \pm 50 \mathrm{mg}$ in controls and $930 \pm 150 \mathrm{mg}$ in the cytokine-treated rodents.

In a second experiment, only food intake and body weights were measured. In this 17-d experiment, animals were injected only intravenously (with $0.25 \mathrm{mg} / \mathrm{kg}$ rHuTNF- $\alpha$ ) at either 5 or 10-d intervals. Fig. 6 shows the results of these dosage regimens on food intake. Injections every $5 \mathrm{~d}$ caused a marked decrease in food intake with the initial injection and a less dramatic decrease following two subsequent injections (Fig. 6 $A$ ). Injections $10 \mathrm{~d}$ apart caused obvious decreases in food intake with both injections (Fig. $6 \mathrm{~B}$ ). The average response to the second injection appeared, again, to be less than the first. Animals showed transitory weight losses on days following injections but gained weight overall. These results suggest that a single injection of rHuTNF- $\alpha$ induces a partial tolerance to the GI response of subsequent injections that persists for at least 5 to $10 \mathrm{~d}$.

In another rat experiment, the effects of daily injections of rHuTNF- $\alpha$ on daily body weights and GI function and morphology after $10 \mathrm{~d}$ of treatment were studied. Fig. 7 compares the effects of two different doses of rHuTNF on body weight with the body weights of animals injected with PBS. Each point represents the mean of 6-10 animals. The higher dose of rHuTNF- $\alpha$ caused a marked loss of weight in the first $3 \mathrm{~d}$ of the experiment but complete recovery of weight loss occurred by day 10 . Animals treated with the lower dose weighed the same as PBS-treated animals. In the high-dose group bloody stools were produced by all animals after the initial injection (two animals died). Some animals from this group were examined histologically $24 \mathrm{~h}$ after their final intramuscular injection.

On day 11 , five control animals and six treated animals (three from each dose) were given an additional intravenous 


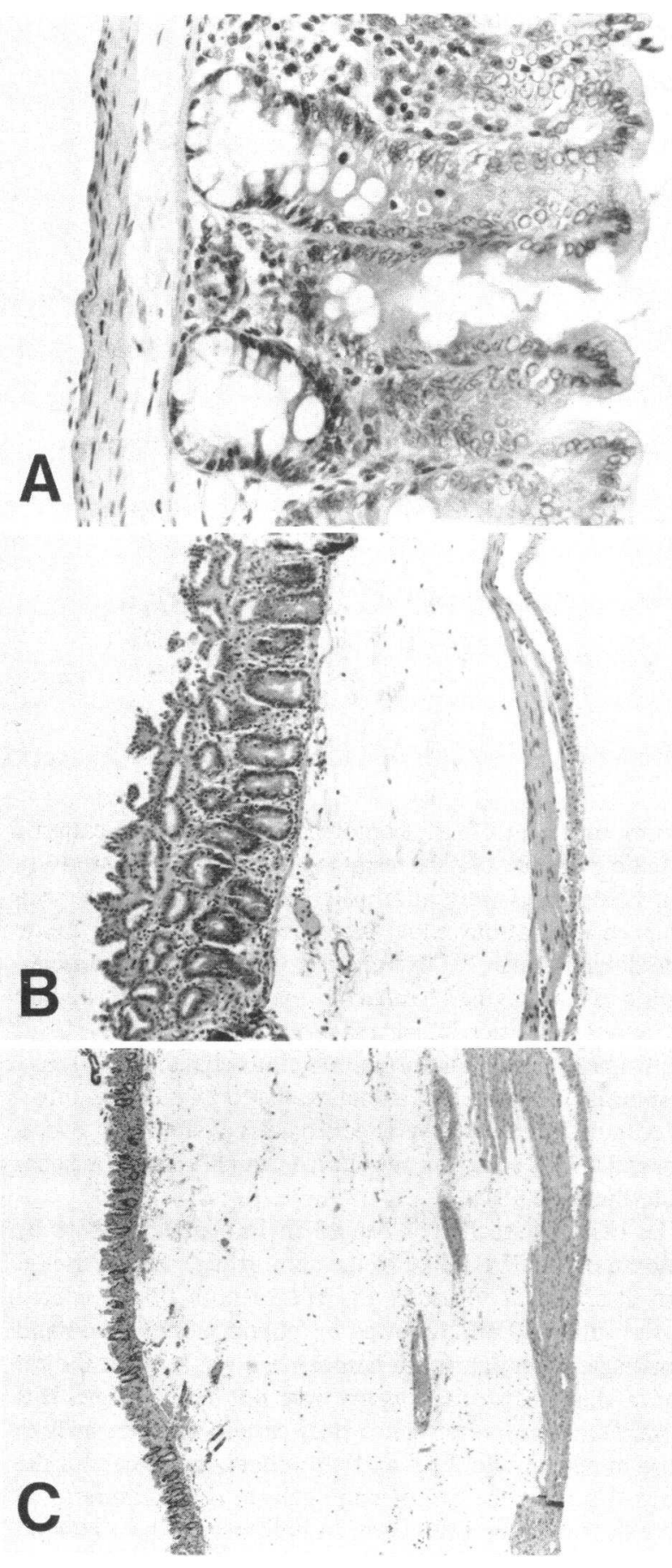

Figure 4. Histological sections stained with hematoxylin-eosin from rat cecum of control $(A), 4 \mathrm{~h}(B)$, and $24 \mathrm{~h}(C)$ postinjected rats and of capillary vessel walls from rat cecum from control $(D), 4 \mathrm{~h}(E)$ and $24 \mathrm{~h}(F)$ postinjected rats. Animals received a single intravenous

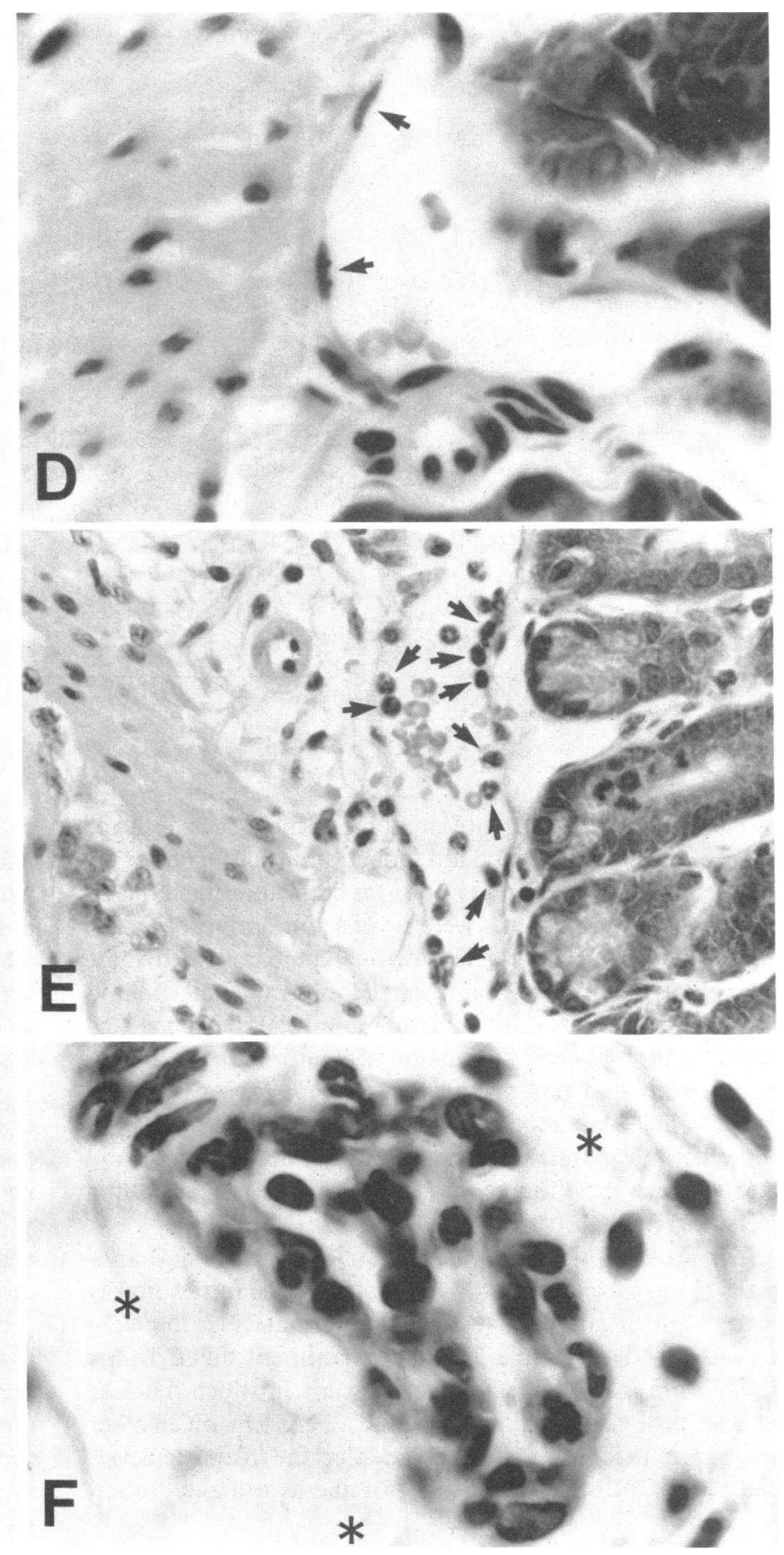

dose of PBS or rHuTNF- $\alpha(0.25 \mathrm{mg} / \mathrm{kg})$. Normal endothelial cells are shown with arrows in $(D)$. Marginated leukocytes are shown with arrows in $(E)$. Note perivascular edema (asterisks) in $(F)$. Magnification was 400 in $A, 160$ in $B, 63$ in $C, 600$ in $D$ and $F$, and 240 in $E$.

$3.5 \mathrm{~h}$ following the final injection, the ceca of treated animals averaged $75 \%$ of the weight of ceca from the control animals, which indicates that defecation was still stimulated after chronic rHuTNF- $\alpha$ treatment.

Histology after multiple injections. Rats injected with rHuTNF- $\alpha$ once daily for $10 \mathrm{~d}$ had histological lesions in the intestine characterized by accumulation of histiocytes (some containing hemosiderin), lymphocytes, eosinophils, and neu- 
Table I. Changes in Blood Components of Rats following a Single Intravenous Injection of rHuTNF- $\alpha(250 \mu \mathrm{g} / \mathrm{kg})$

\begin{tabular}{|c|c|c|c|c|}
\hline \multirow[b]{2}{*}{ Postinjection } & \multicolumn{2}{|l|}{ Males } & \multicolumn{2}{|l|}{ Females } \\
\hline & PBS & rHuTNF- $\alpha$ & PBS & rHuTNF- $\alpha$ \\
\hline \multicolumn{5}{|l|}{$h$} \\
\hline \multicolumn{5}{|c|}{ Neutrophils/mm $\mathrm{mm}^{3}$} \\
\hline 1.5 & $1,784 \pm 617(6)^{*}$ & $1,500 \pm 940(6)$ & $865 \pm 846(4)$ & $672 \pm 332(4)$ \\
\hline 3.0 & $2,093 \pm 959(6)$ & $8,772 \pm 3,384(5)$ & $1,189 \pm 746(5)$ & $5,815 \pm 1,281(5)$ \\
\hline 4.5 & $2,495 \pm 1,312(6)$ & $9,580 \pm 2,595(6)$ & $991 \pm 661(6)$ & $5,316 \pm 1,831(5)$ \\
\hline \multicolumn{5}{|c|}{ Lymphocytes $/ \mathrm{mm}^{3}$} \\
\hline 1.5 & $6,432 \pm 1,882(6)$ & $4,279 \pm 1,039$ & $3,901 \pm 846$ & $4,054 \pm 861(4)$ \\
\hline 3.0 & $7,570 \pm 1,817(6)$ & $4,256 \pm 2,248(5)$ & $8,318 \pm 2,214(5)$ & $3,542 \pm 867(5)$ \\
\hline 4.5 & $8,253 \pm 2,120(6)$ & $2,000 \pm 2,032(6)$ & $6,359 \pm 1,598(6)$ & $3,971 \pm 2,490(5)$ \\
\hline \multicolumn{5}{|c|}{ Triglycerides (mg/dl) } \\
\hline 3.5 & - & - & $67 \pm 22(4)$ & $210 \pm 55(4)$ \\
\hline 7.0 & - & - & $43 \pm 13(4)$ & $258 \pm 130(4)$ \\
\hline
\end{tabular}

$* \pm 1 \mathrm{SD}(n=$ number of animals).

trophils. Varying numbers of mixtures of these cells occurred throughout the submucosa and lamina propria (Fig. 8) of the cecum and occasionally other portions of the intestine. Inflammatory cell accumulations were several times more severe in rats receiving $0.25 \mathrm{mg} / \mathrm{kg}$ rHuTNF- $\alpha$ compared with those receiving $0.025 \mathrm{mg} / \mathrm{kg}$. There was slight to moderate submucosal edema and lymphatic dilitation in several sites associated with both dose levels. Margination of neutrophils to vascular endothelium was not prominent. Several foci, present in cecum of high-dose rats, were composed of mixed inflammatory cells and granulation tissue that replaced mucosa and extended into the submucosa. These foci resembled healing ulcers (Fig. $8 \mathrm{D}$ ).

Time course of antibody formation. Anti-rHuTNF- $\alpha$ antibodies began to appear by day 10 in rats injected intravenously on day 1 and all subsequent days intramuscularly $(0.25 \mathrm{mg} / \mathrm{kg}$ per d rHuTNF- $\alpha$ ) (Table II). This experiment differed only slightly from the first metabolic cage study in which the dose was administered i.v. on days 0,5 , and 12 and i.m. on all other days. From these results we conclude that the tolerance developed to rHuTNF- $\alpha$ by day 5 was not due to antibody formation.

\section{Discussion}

TNF had two major effects on the gastrointestinal tract of rats. It cleared the small and large intestine of nutrients by inhibiting gastric emptying and accelerating movement of intestinal contents out of the animal, and it induced the flow of fluid (edema) and leukocytes into the GI tissue. Conceivably during intestinal infection these effects could be complementary and beneficial. Removal of intestinal contents would stop the flow of dietary nutrients into the intestinal tissue and bloodstream thereby reducing the accessibility of nutrients to pathogens. Clearing of intestinal contents would also reduce the numbers of intestinal microflora that might otherwise become invasive during GI inflammation and edema would open spaces in the tissue for easier foraging by the host's newly activated phago- cytic immune cells. Clearly hemorrhage represents an extreme and toxic example of this response. In the present study in which bolus doses were administered, hemorrhage was seen only at concentrations equal to or above $250 \mu \mathrm{g} / \mathrm{kg}^{2}$ Acute febrile diseases cause GI dysfunction in most animal species. Injection of endotoxin, Mycobacterium, and Newcastle disease virus causes inhibition of gastric motility in goats (29). Thus TNF, which is produced during infectious challenge (30) may be responsible for the GI dysfunction that occurs during infection. Although the negative effects of this dysfunction over a prolonged period are clear, the short-term effect may be beneficial to the host (13).

The hemorrhage that is caused in implanted tumors by endotoxin or TNF is similar to the hemorrhage seen in the rat cecum at similar TNF doses $(4,31)$. In both tissues edema occurred within 30 min followed by leukocyte infiltration and hemorrhage. Although some hemorrhage was seen in the rat uterus in this study, other organs were not hemorrhagic. It is uncertain what properties allow only certain vascular beds to rupture in response to TNF and not others. In the case of the implanted tumor, the tumor endothelium is immature ( $8 \mathrm{~d}$ ) relative to that in the rat cecum. In both tissues there is rapid cell division. Endothelial cells in culture have been shown to possess $\sim 1,500$ high affinity TNF receptors per cell (3). Perhaps the number of endothelial TNF receptors and/or the response of endothelium to TNF varies from tissue to tissue. Since the rat cecum contains a large microbial community, and is at constant risk of microbial invasion, a high responsiveness to TNF may insure a robust inflammatory response should infection occur.

2. Such doses are more than 50 times the current estimates for the maximally tolerated single dose in man and far above those recommended for phase II studies in man (27). However, TNFs exhibit some species specificity and the $\mathrm{LD}_{50}$ of human TNF in rodents appears to be at least an order of magnitude higher than the $\mathrm{LD}_{50}$ of murine TNF in rodents $(4,28)$. 


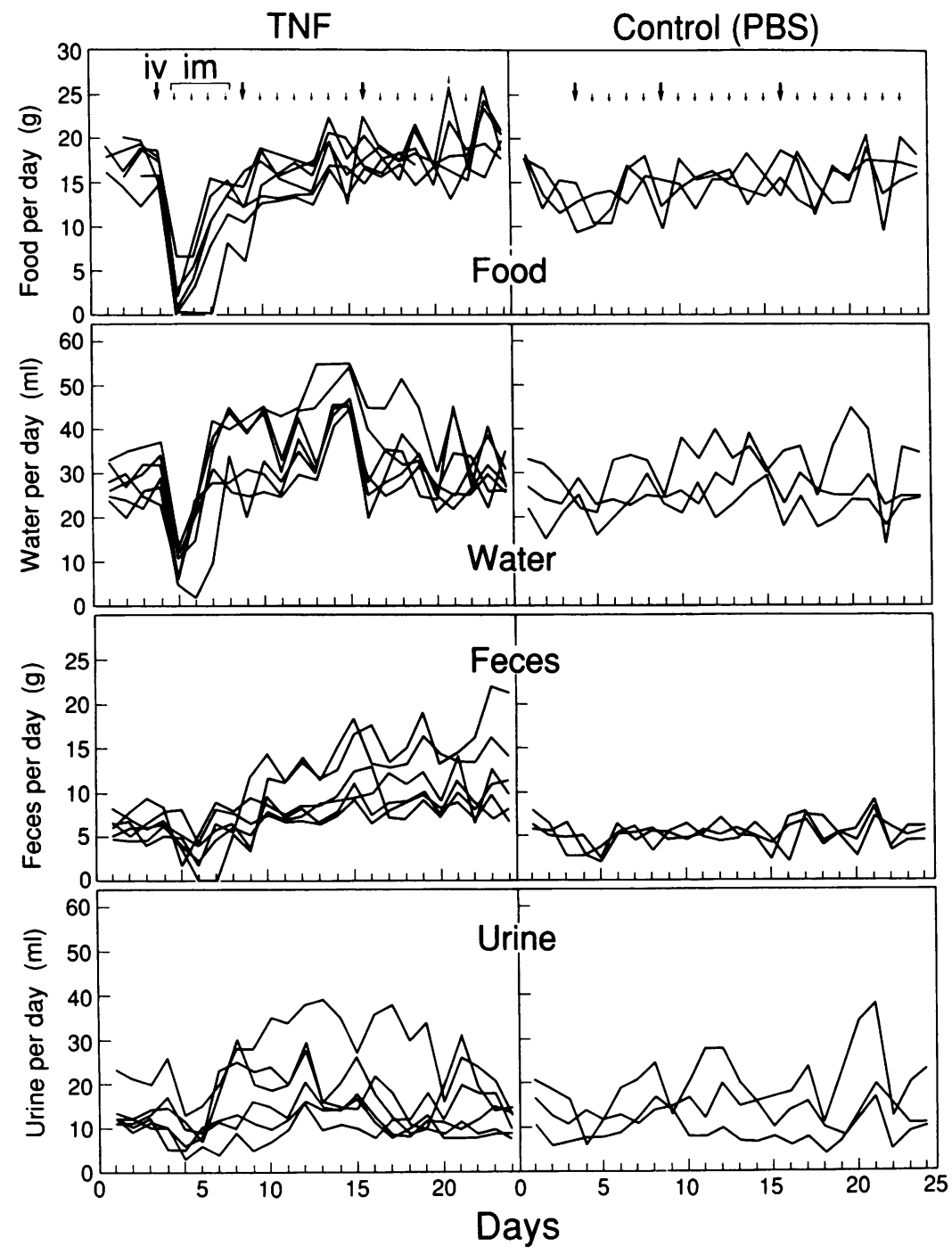

Figure 5. The effect of daily injections of rHuTNF- $\alpha$ $(0.25 \mathrm{mg} / \mathrm{kg})$ or PBS on daily consumption and excretion of nine rats (six rHuTNF- $\alpha$ treated, three controls). After $3 \mathrm{~d}$ of acclimation, daily injections were initiated. Intravenous injections (large arrows) were mixed with intramuscular injections (small arrows) as shown at the top of the panels. Individual measurements were made at $24-\mathrm{h}$ intervals and the lines represent the connection of these values.

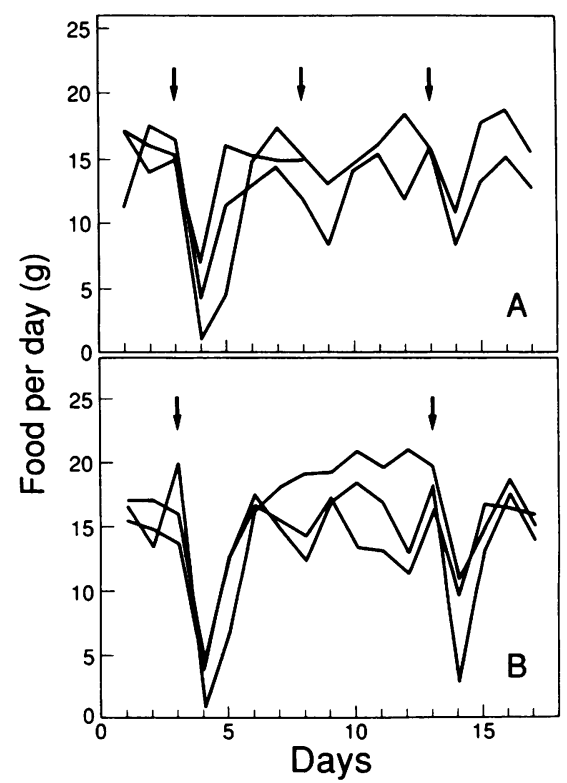

Figure 6. The effect of rHuTNF- $\alpha(0.25 \mathrm{mg} / \mathrm{kg}$ per injection) on daily food intake of six rats receiving single intravenous injections at 5 day $(A)$, or $10 \mathrm{~d}(B)$ intervals. One of the three rats in the $5-\mathrm{d}$ interval study died on day 9 .
The effects of rHuTNF- $\alpha$ on rodent GI tracts apparently persist long after the cytokine has been cleared from the blood. Three groups have shown that TNF is rapidly cleared from the blood $\left(t_{1 / 2}<20 \mathrm{~min}\right)(32-34)$ and the liver, kidneys, spleen,

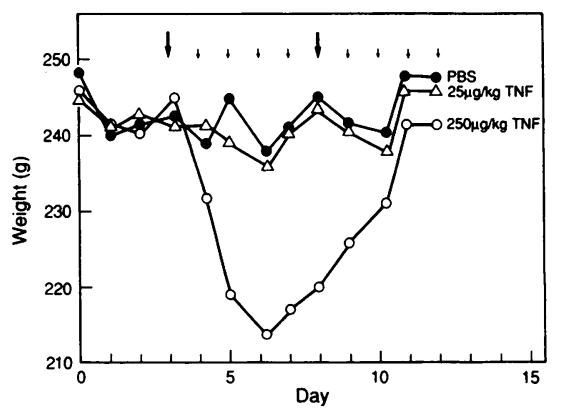

Figure 7. The effect of daily injections of two doses of rHuTNF- $\alpha$ or PBS on total body weight of rats. After monitoring weights for $4 \mathrm{~d}$, injections were initiated. Intravenous injections (large arrows) were mixed with intramuscular injections (small arrows) as shown at the top of the graph. Each point represents the mean of 6-10 animals (standard deviations averaged 3-4\% of the mean). 

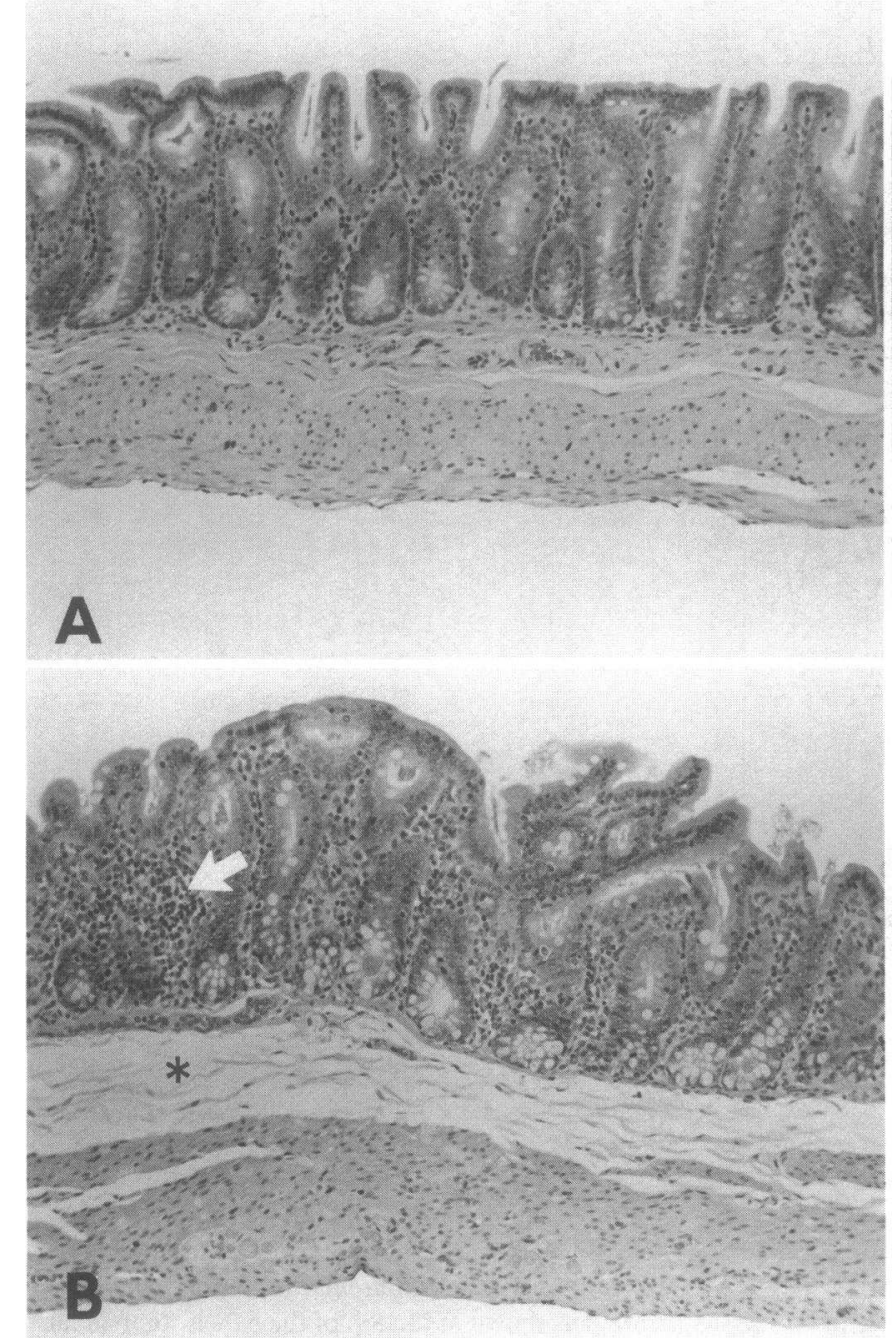

Figure 8. The effect of the 10-d treatments shown in Fig. 7 on rat cecal morphology. $(A)$ Control cecum (PBS). (B) Low-dose treatment $(0.025 \mathrm{mg} / \mathrm{kg})$ showing some edema (asterisk) and excess inflammatory cells (arrow). $(C)$ High-dose treatment $(0.25 \mathrm{mg} / \mathrm{kg})$ showing large accumulation of inflammatory cells in submucosa (arrows) and

and GI tract all concentrate injected ${ }^{125} \mathrm{I}-\mathrm{TNF}-\alpha$ relative to plasma (33). The GI tract has been shown to accumulate 9\% of the total injected TNF after $8 \mathrm{~min}$ in mice (32). However, once bound to tissue, TNF is rapidly degraded (32), thus, the

Table II. Appearance of Antibodies to rHuTNF- $\alpha$ in Rat Sera following Daily Injections for $3 \mathrm{Wk}$ of $\mathrm{rHuTNF}-\alpha(0.25 \mathrm{mg} / \mathrm{kg} / \mathrm{d})$

\begin{tabular}{rll}
\hline Day & Antibodies $^{\ddagger}$ & Total antibodies \\
\hline & $n g$ TNF neutralized/ml serum & titer \\
0 & 0 & 0 \\
2 & 0 & 0 \\
4 & 0 & 0 \\
6 & 0 & 0 \\
8 & 0 & 0 \\
10 & 0 & $0.7 \pm 1.1(3)$ \\
12 & $421 \pm 103(6)$ & $3.6 \pm 0.8(3)$ \\
\hline
\end{tabular}

* All injections were i.m. except the first one (see Methods for details).

$\ddagger$ Mean \pm 1 SD ( $n$, number of animals in parentheses).
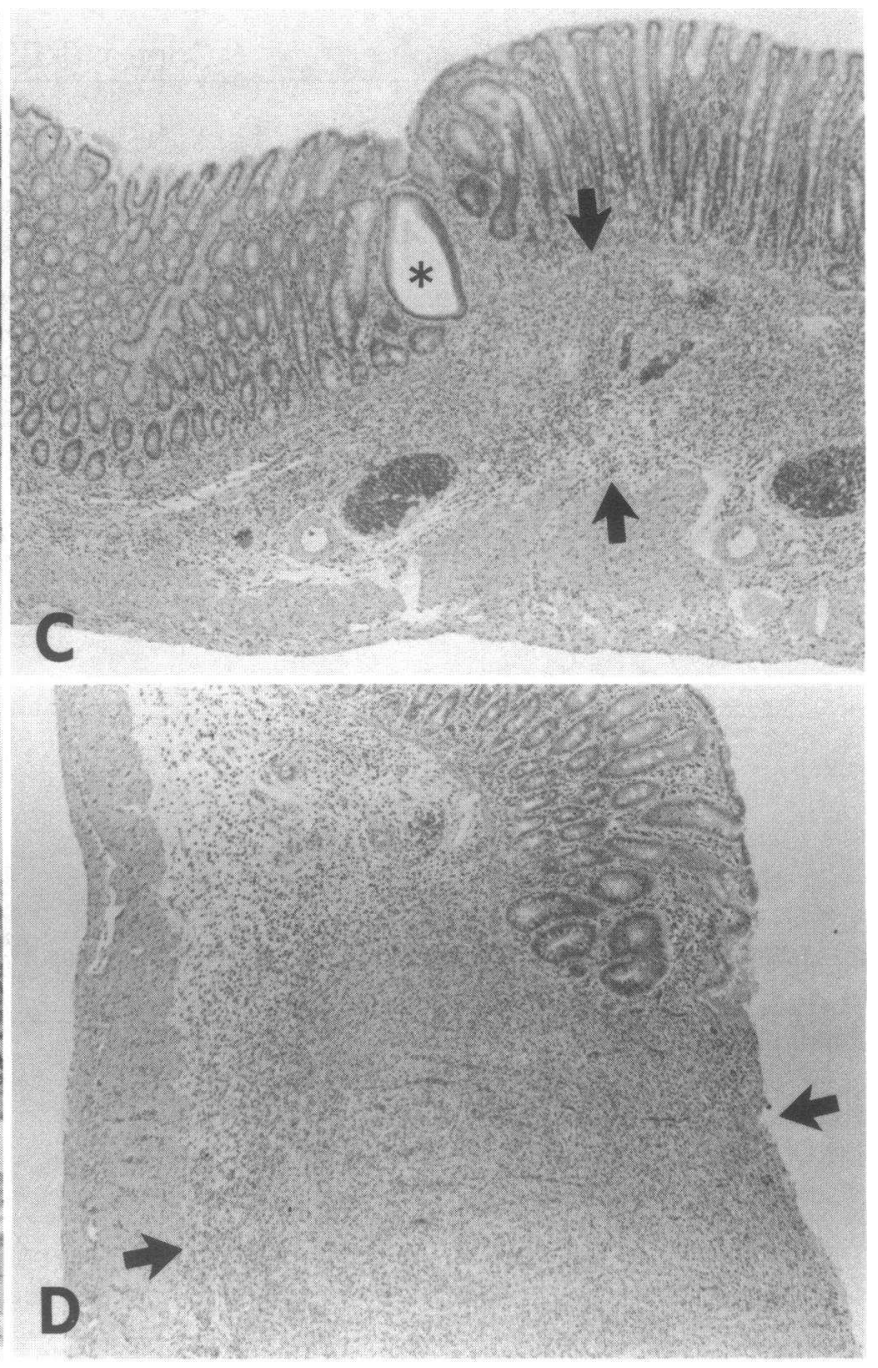

a dilated crypt (asterisk). (D) High-dose treatment showing region of rat cecum where mucosa is replaced by a large accumulation (arrow) of inflammatory cells and fibroblasts representing a healing ulcer. Magnification was 200 in $A$ and $B$ and 160 in $C$ and $D$.

GI effects caused by rHuTNF- $\alpha$ seem to be induced by a brief circulatory exposure to the cytokine.

Although a variety of cytokines possess catabolic activity in vitro (35), TNF is thought by some to be the agent responsible for wasting in infected animals (30). In this study there was a dramatic drop in food intake at the beginning of TNF treatment; however, the effect was transitory and food intake rebounded within $48 \mathrm{~h}$. Weight loss, which occurred only in the high dose group, was also transitory and coincided with the drop in food intake and GI hemorrhage that followed the first intravenous injection. Rebound from the weight loss began by day 3 , which was $7 \mathrm{~d}$ before neutralizing antibodies could be detected. Although Cerami and co-workers demonstrated wasting in mice injected twice daily, intraperitoneally with activated macrophage medium (20), their study is not directly comparable to this one. Their medium may have contained a variety of agents besides TNF including endotoxin and interleukin 1 (19); their delivery schedule (twice per day) differed from that used in the present study (once per day); and their route of administration was different (intraperitoneal versus intravenous or intramuscular). Since tolerance did not develop 
to the inhibitory effect of rHuTNF- $\alpha$ on gastric emptying it is conceivable that weight loss from gastric blockage could occur with more frequent doses of TNF, particularly intraperitoneal doses that may deliver elevated and sustained cytokine levels to the GI tract. In this study rHuTNF- $\alpha$ induced retention of stomach contents was detectable for $\sim 6-7 \mathrm{~h}$ after an intravenous dose. Intramuscular injections caused a milder response. Clearly the animals were able to compensate for this disruption of gastric function and to grow. Perhaps during infection pulsatile production of TNF occurs with a high enough frequency that feeding is chronically suppressed and wasting occurs, or alternatively, high sustained levels produce the same effect. Further studies are underway to determine if TNF-induced gastric blockage is an important mechanism in cachexia. To date, there is no evidence that pure TNF causes wasting.

Quick adaptation to rHuTNF- $\alpha$ occurred in the rats such that the severe GI toxicity of the initial injection did not reappear with subsequent doses unless they were intermittent (every 5 or $10 \mathrm{~d}$ ). Much of the inflammatory change in the intestine seen after $10 \mathrm{~d}$ of chronic dosing was probably associated with a normal healing response that followed the acute injury induced by the initial injection. However, chronic irritation associated with secondary microbial infections or other persistent chemotactic stimuli should also be considered as possible complicating factors. The relative increase in fecal weights in some of the rHuTNF- $\alpha$-treated animals following the initial dosing probably reflect the period in which healing of the large bowel was occurring and digestion and absorption of cecal material was less efficient. Increased fecal weight could also be due to absorption by the feces of fluid lost to the intestinal lumen associated with inflammation and edema.

The rapid development of tolerance (tachyphylaxis) to the hemorrhagic effects of rHuTNF- $\alpha$ on the GI tract is similar to the tolerance seen in humans to some of the adverse side-effects of alpha interferon. Sherwin et al. (15) reported tachyphylaxis with fever, flulike symptoms, and GI effects, whereas fatigue and anorexia tended to be cumulative. Lau et al. have shown in vivo and in vitro that alpha interferon receptor numbers on human blood lymphocytes decreased nearly 10-fold after interferon treatment and required roughly $72 \mathrm{~h}$ to recover (36). During the recovery period the cells also exhibited hyporesponsiveness to interferon treatment (36). Thus, down regulation of TNF receptors is a possible cause of the tolerance seen in this study.

In summary, these results suggest that rodents are primed to respond acutely to TNF with an inflammatory response. It remains to be seen how dramatic this effect is in all tissues (37); however, the response can lead to vascular compromise, edema, hemorrhage, and with some implantable tumors this may result in a cure. Since the response requires a recovery period before it can recur it might be appropriate to use interval rather than continuous dosing for tumor therapy.

\section{Acknowledgments}

We thank Bryan Finkle, Michael Palladino, Steve Sherwin, and Sam Saks for critical comments.

Note added in proof. Rothstein and Schreiber (38) have shown that endotoxin and rHuTNF exhibit synergistic toxicity in mice. This could explain why the cecum, which contains high levels of endotoxin, exhibited such a dramatic hemorrhagic response to TNF.

\section{References}

1. Carswell, E. A., L. J. Old, R. C. Kassel, S. Green, N. Fiore, and B. Williamson. 1975. An endotoxin-induced serum factor that causes necrosis of tumors. Proc. Natl. Acad. Sci. USA. 72:3666-3670.

2. Goeddel, D. V., B. B. Aggarwal, P. W. Gray, D. W. Leung, G. E. Nedwin, M. A. Palladino, J. S. Patton, D. Pennica, H. M. Shepard, B. J. Sugarman, and G. H. W. Wong. 1986. Tumor necrosis factors: gene structure and biological activities. Cold Spring Harbor Symposium. 51:597-609.

3. Nawroth, P. P., I. Bank, D. Handley, J. Cassimeris, L. Chess, and D. Stern. 1986. Tumor necrosis factor/cachectin interacts with endothelial cell receptors to induce release of interleukin 1. J. Exp. Med. 163:1363-1375.

4. Palladino, M. A., Jr., M. R. Shalaby, S. M. Kramer, A. B. DeLeo, D. Crase, B. M. Marafino, B. B. Aggarwal, D. Liggit, and J. S. Patton. 1987. Characterization of the antitumor activities of human tumor necrosis factor-alpha and the comparison with other cytokines. Induction of tumor specific immunity. J. Immunol. 138:4023-4032.

5. Gamble, J. R., J. M. Harlan, S. J. Klebanoff, and M. A. Vadas. 1985. Stimulation of the adherence of neutrophils to umbilical vein endothelium by human recombinant tumor necrosis factor. Proc. Natl. Acad. Sci. USA. 82:8667-8671.

6. Pohlman, T. H., K. A. Stanness, P. G. Beatty, H. D. Ochs, and J. M. Harlan. 1986. An endothelial cell surface factor(s) induced in vitro by lipopolysaccharide, interleukin-1, and tumor necrosis factor- $\alpha$ increases neutrophil adherence by a CDW18-dependent mechanism. J. Immunol. 136:4548-4553.

7. Shalaby, M. R., B. B. Aggarwal, E. Rinderknecht, L. P. Svedersky, B. S. Finkle, and M. A. Palladino. 1985. Activation of human polymorphonuclear neutrophil functions by gamma interferon and tumor necrosis factors. J. Immunol. 135:2069-2073.

8. Weiss, S. J., J. Young, A. F. Lobuglio, A. Slivka, and N. F. Nimeh. 1981. Role of hydrogen peroxide in neutrophil-mediated destruction of cultured endothelial cells. J. Clin. Invest. 68:714-721.

9. Harlan, J. M. 1985. Leukocyte-endothelial interactions. Blood. 65:513-525.

10. Sugarman, B. J., B. B. Aggarwal, P. E. Hass, J. S. Figari, M. A. Palladino, and H. M. Shepard. 1985. Recombinant human tumor necrosis factor $\alpha$ : effects on proliferation of normal and transformed cells in vitro. Science (Wash. DC). 230:943-945.

11. Urban, J. L., H. Michael Shepard, J. L. Rothstein, B. J. Sugarman and H. Schreiber. 1986. Tumor necrosis factor: a potent effector molecule for tumor cell killing by activated macrophages. Proc. Natl. Acad. Sci. USA. 83:5233-5237.

12. Fung, K. P., S. W. Leung, D. K. K. Ha, S. W. Ng, Y. M. Choy, and C. Y. Lee. 1985. Effect of tumor necrosis factor on growth of Ehrlich ascites tumor cells in vitro and in vivo. Cancer Lett. 27:269276.

13. Murray, M. J., and A. B. Murray. 1979. Anorexia of infection as a mechanism of host defense. Am. J. Clin. Nutr. 32:593-596.

14. Murray, M. J., and A. B. Murray. 1977. Hypothesis-starvation suppression and refeeding activation of infection. Lancet. ii:123-125.

15. Murray, M. J., and A. B. Murray. 1977. Suppression of infection by famine and its activation by refeeding-a paradox. Perspect. Biol. Med. 20:471-483.

16. Sherwin, S. A., J. A. Knost, S. Fein, P. G. Abrams, K. A. Foon, J. J. Ochs, C. Schoenberger, A. E. Maluish, and R. K. Oldham. 1982. A multiple-dose phase I trial of recombinant leukocyte $\mathrm{A}$ interferon in cancer patients. J. Am. Med. Assoc. 248:2461-2466.

17. Vadhan-Raj, S., A. Al-Katib, R. Bhalla, L. Pelus, C. F. Nathan, S. A. Sherwin, H. F. Oettgen, and S. E. Krown. 1986. Phase I trial of recombinant interferon gamma in cancer patients. J. Clin. Oncol. 4:137-146.

18. McCarthy, D. O., Kluger, M. J., and A. J. Vander. 1985. Suppression of food intake during infection. Am. J. Clin. Nutr. 42:11791182.

19. Dinarello, C. A. 1984. Interleukin-1. Rev. Infect. Dis. 6:51-95. 20. Cerami, A., Y. Ikeda, N. LeTrang, P. J. Hotez, and B. Beutler. 
1985. Weight loss associated with an endotoxin-induced mediator from peritoneal macrophages. The role of cachectin (tumor necrosis factor). Immunol. Lett. 11:173-177.

21. Pennica, D., G. E. Nedwin, J. S. Hayflick, P. H. Seeburg, R. Derynck, M. A. Palladino, W. J. Kohr, B. B. Aggarwal, and D. V. Goeddel. 1984. Human tumor necrosis factor: cDNA cloning, expression, and homology to lymphotoxin. Nature (Lond.). 312:724-729.

22. Gray, P. W., B. B. Aggarwal, C. V. Benton, T. S. Bringman, W. J. Henzel, J. A. Jarrett, D. W. Leung, B. Moffat, P. Ng, L. P. Svedersky, M. A. Palladino, and G. E. Nedwin. 1984. Cloning and expression of $\mathrm{cDNA}$ for human lyphotoxin, a lymphokine with tumor necrosis activity. Nature (Lond.). 312:721-724.

23. Gray, P. W., and D. V. Goeddel. 1983. Cloning and expression of murine immune interferon cDNA. Proc. Natl. Acad. Sci. USA. 80:5842-5846.

24. Pennica, D., J. S. Hayflick, T. Bringman, M. A. Palladino, and D. V. Goeddel. 1985. Cloning and expression in E. coli of the cDNA for murine tumor necrosis factor. Proc. Natl. Acad. Sci. USA. 82:6060-6064.

25. Aggarwal, B. B., T. E. Eessalu, and P. E. Hass. 1985. Characterization of receptors for human tumor necrosis factor and their regulation by $\gamma$-interferon. Nature (Lond.). 318:665-667.

26. Kramer, S. M., and Carver, M. E. 1986. Serum-free in vitro bioassay for the detection of tumor necrosis factor. J. Immunol. Methods. 93:201-206.

27. Blick, M. B., S. A. Sherwin, M. G. Rosenblum, and J. U. Gutterman. 1986. A Phase I trial of recombinant tumor necrosis factor (rTNF) in cancer patients. Proc. Am. Soc. Clin. Oncology. 5:14. (Abstr.)

28. Smith, R. A., M. Kirstein, W. Fiers, and C. Baglioni. 1986. Species specificity of human and murine tumor necrosis factor. A comparative study of tumor necrosis factor receptors. J. Biol. Chem. 261:14871-14874.

29. van Miert, A. S. J. P. A. M., and C. Th. M. van Duin. 1974. The effects of bacterial pyrogens and leucocytic pyrogen upon gastric motil- ity and heart rate frequency in conscious goats. Zbl. Vet. Med. A. 21:692-702.

30. Beutler, B., and A. Cerami. 1986. Cachectin and tumor necrosis factor as two sides of the same biological coin. Nature (Lond.). 320:584-588.

31. Freudenberg, M., K. Joh, O. Westphal, C. H. Mittenmayer, M. A. Freudenberg, and C. H. Galanos. 1984. Haemorrhagic tumor necrosis following endotoxin administration. Virchows. Arch. A. Pathol. Anat. Histol. 403:377-389.

32. Beutler, B. A., I. W. Milsark, and A. Cerami. 1985. Cachectin/ tumor necrosis factor: production, distribution, and metabolic fate in vivo. J. Immunol. 135:3972-3977.

33. Flick, D. A., and G. A. Gifford. 1986. Pharmacokinetics of murine tumor necrosis factor. J. Immunopharmacol. 8:89-97.

34. Baughman, R. A., B. Ferraiolo, R. Vandlen, B. Aggarwal, and J. A. Moore. 1986. Pharmacokinetics and tissue distribution of recombinant tumor necrosis factor alpha in rodents. Pharmacol. Res. 3:141a. (Abstr.)

35. Patton, J. S., M. S. Shepard, H. Wilking, G. Lewis, B. B. Aggarwal, T. E. Eessalu, L. A. Gavin, and C. Grunfeld. 1986. Interferons and tumor necrosis factors have similar catabolic effects on $3 \mathrm{~T} 3 \mathrm{L1}$ cells. Proc. Natl. Acad. Sci. USA. 83:8313-8317.

36. Lau, A. S., G. E. Hannigan, M. H. Freedman, and B. R. G. Williams. 1986. Regulation of interferon receptor expression in human blood lymphocytes in vitro and during interferon therapy. $J$. Clin. Invest. 77:1632-1638.

37. Tracey, K. J., B. Beutler, S. F. Lowry, J. Merryweather, S. Wolpe, I. W. Milsark, R. J. Hariri, T. J. Fahey III, A. Zewntella, J. D. Albert, G. T. Shires, and A. Cerami. 1986. Shock and tissue injury induced by recombinant human cachectin. Science (Wash. DC). 234:470-474.

38. Rothstein, J. L., and H. Schreiber. 1988. Synergy between tumor necrosis factor and bacterial components in causing hemorrhagic necrosis and lethal shock in normal mice. Proc. Natl. Acad. Sci. USA. In press. 